\title{
ANZ, Christoph, Gilden im mittelalterlichen Skandinavien
}

Jean-Marie Maillefer

\section{OpenEdition}

Journals

Édition électronique

URL : http://journals.openedition.org/ifha/1352

DOI : 10.4000/ifha.1352

ISSN : 2198-8943

\section{Éditeur}

IFRA - Institut franco-allemand (sciences historiques et sociales)

Référence électronique

Jean-Marie Maillefer, «ANZ, Christoph, Gilden im mittelalterlichen Skandinavien », Revue de l'IFHA [En ligne], Date de recension, mis en ligne le 01 janvier 1999, consulté le 22 septembre 2020. URL : http:// journals.openedition.org/ifha/1352 ; DOI : https://doi.org/10.4000/ifha.1352

Ce document a été généré automatiquement le 22 septembre 2020.

(CIFHA 


\title{
ANZ, Christoph, Gilden im mittelalterlichen Skandinavien
}

\author{
Jean-Marie Maillefer
}

Depuis une vingtaine d'années les historiens allemands ont abondamment repris la question des guildes si l'on en juge par les les ouvrages de Klaus FRIEDLAND (dir.), Gilde und Korporation in den nordeuropäischen Städten des späten Mittelalters, Köln: Böhlau, 1984, de Berent SCHWINEKÖPER (dir.), Gilde und Zünfte. Kaufmännische und gewerbliche Genossenschaften im frühen und hohen Mittelalter, Sigmaringen: Thorbecke, 1985 ou de Peter JOHANEK (dir.), Einungen und Bruderschaften in der spätmittelalterlichen Stadt, Köln: Böhlau (Städteforschung Reihe A, Darstellungen, 32), 1993. Chr.A. ajoute à ce tableau une mise au point bienvenue sur la situation des guildes en Scandinavie médiévale jusqu'à la Réforme. Auparavant, il dresse un panorama de l'historiographie du sujet depuis le milieu du XVIIIe s. tant sur le continent (p. 19-36, surtout en Allemagne) qu'en Scandinavie, c'est-à-dire dans les royaumes de Danemark, de Norvège et de Suède (p. 37-55). L'auteur discute ensuite la notion de guilde, phénomène multiforme, comme l'atteste la multiplicité de la terminologie (societas, conjuratio, confraternitas etc.), notamment en Scandinavie (p. 57-72). Il présente dans un troisième temps l'état des sources, surtout normatives mais où l'on trouve aussi des actes de fondations, des listes de membres et des chartes de donations (p. 78-82): si la Norvège n'a conservé que trois statuts de guildes du Moyen Âge, plusieurs dizaines ont été édités au Danemark et la Suède conserve une ensemble unique avec les archives de la Helga Lekamens gille de Stockholm. Cela montre l'importance des guildes dans les sociétés scandinaves au Moyen Âge. L'auteur aborde ensuite le cœur proprement dit de son étude: il passe en revue les guildes, leurs formes et leurs manifestations en Norvège (p. 83-126), en Suède (p. 127-183) et au Danemark (p. 184-252). Il replace enfin les guildes scandinaves dans un contexte social plus large, développant en particulier leur situation vis-à-vis de l'Église (p. 254-263) puis leur rapport avec le pouvoir royal (263-281). L'ouvrage comprend une bibliographie importante où les livres en langue française ne sont pas oubliés (ainsi celui de M. Cahen sur la libation paru en 1921). On comprend d'autant moins que les parutions les plus récentes du Diplomatarium suecanum ne soient pas mentionnées après 1960, particulièrement les tomes VII: 1-6 
(1976-1991); VIII: 1 (1953!), VIII: 2 (1964), VIII: 3 (1966), VIII: 4 (1976) et X: 1-2 (1970-1974). L'intérêt de l'étude de Chr.A. est de tenter une synthèse sur le phénomène des guildes en Scandinavie, sujet qui attendait d'être renouvelé après les recherches menées par les historiens nordiques au XIXe s. et dans la première moitié du XXe s. L'auteur rejette l'idée d'une continuité entre les associations germaniques païennes (Männerbund-Theorie) et les guildes médiévales où la dimension chrétienne est omniprésente. Sa réfutation n'est peut-être pas entièrement convaincante, car si l'on peut récuser des témoignages de seconde main sur l'existence de communautés de ce type à l'époque viking (comme les affirmations de Snorri Stuluson dans la saga de Háon le bon, chap. 14), on possède la trace d'un compagnonnage juré (félag), guerrier mais aussi commercial, à travers des inscriptions runiques. Ce n'est pourtant qu'à partir du XIIe s. que les guildes sont indubitablement attestées en Scandinavie où elles apparaissent plus tardivement que sur le continent. Chr.A. insiste notamment sur l'aspect religieux et commémoratif particulièrement marqué dans les guildes scandinaves. Son ouvrage a aussi le mérite de retracer clairement en Allemagne et en Scandinavie le débat historiographique sur le problème de l'origine et de la définition des guildes, qui furent d'abord des associations de personnes se vouant assistance mutuelle et protection, dans un but religieux et économique. Au-delà de certains particularismes nordiques (la présence de guildes dans le monde rural par exemple), ce livre est une nouvelle démonstration de l'appartenance de la Scandinavie à la civilisation médiévale occidentale.

Jean-Marie MAILLEFER 